\title{
Viability and Cell Biology for Hela and Vero Cells after Exposure to Low-Temperature Air Dielectric Barier Disc harge Plasma
}

\author{
Ioana Cristina Gerber, ${ }^{a}$ Cosmin Teodor Mihai, ${ }^{b}$ Lucian Gorgan, ${ }^{c}$ Mitica \\ Ciorpac, ${ }^{\mathrm{b}}$ Alexandru Nita, ${ }^{\mathrm{c}}$ Valentin Pohoata, ${ }^{\mathrm{a}}$ llarion Mihaila, ${ }^{\mathrm{d}}$ \& Ionut Topala ${ }^{\mathrm{a},{ }^{*}}$ \\ ${ }^{a}$ Alexandru Ioan Cuza University of Iasi, Faculty of Physics, Iasi Plasma Advanced Research Center (IPARC), \\ Iasi, 700506, Romania; 'Alexandru Ioan Cuza University of Iasi, Interdisciplinary Research Department, \\ Field Science, Iasi, 700506, Romania; 'Alexandru Ioan Cuza University of Iasi, Faculty of Biology, Iasi, \\ 700506, Romania; dAlexandru Ioan Cuza University of Iasi, Integrated Center of Environmental Science \\ Studies in the North-Eastern Development Region (CERNESIM), Iasi, 700506, Romania \\ *Address all correspondence to: Ionut Topala, Alexandru Ioan Cuza University of Iasi, Faculty of Physics, Iasi Plasma \\ Advanced Research Center (IPARC), Bd. Carol I No. 11, Iasi, 700506, Romania; Tel.: +40232201188; Fax: +40232201150, \\ E-mail: ionut.topala@uaic.ro
}

\begin{abstract}
Cancer study is among the hottest topics in plasma medicine. Differential killing of cancer cells and controllable selectivity may be achieved using exposure to plasma generated by various atmospheric pressure discharges. In this article, we discuss the possibility of generating low-temperature air plasma directly inside standard 24- and 96-well cell-culture plates and its subsequent use to achieve selective cytotoxicity. After exposure, cell viability was assessed and molecular biology tests carried out to understand the effect of plasma on cell biology. HeLa (neoplastic cells) and Vero (normal cells) cultures were exposed to air dielectric barrier discharge plasma. We performed viability assessment using the 3-(4,5-dimethylthiazol-2-yl)-2,5-diphenyltetrazolium bromide assay at 8 and $24 \mathrm{hr}$ after treatment and found a reduction in cell viability, with a variable amplitude of effect. The cytotoxicity of plasma on HeLa cells at $8 \mathrm{hr}$ was $59.92 \%$ and reached $68.58 \%$ by $24 \mathrm{hr}$. The cytotoxic effect on Vero cells was limited to $37.75 \%$ at $8 \mathrm{hr}$ and only $6.33 \%$ at $24 \mathrm{hr}$. General cell biology analyses were assessed using flow cytometry and gene expression tracking.
\end{abstract}

KEY WORDS: air DBD plasma, cytotoxicity, apoptosis, TP53

\section{INTRODUCTION}

Many technological operations now use various forms of atmospheric pressure plasmas. Well-known examples originate from cutting, welding, printing, and thin-layerdeposition plasma-based devices. ${ }^{1,2}$ The expertise in plasma-based device design for heat-sensitive material processing presented the opportunity for direct plasma exposure of soft biological matter. Unlike inert matter, plasma exposure of cells, tissues, or living organisms induces an active response as well as common physicochemical modifications that must not exceed safety limits.

The progress in the field of plasma medicine is ensured nowadays ensured by the network of physicists, medical doctors, and biologists. Many applications of plasma sources in life sciences are now transferred to clinical use and different medical trials 
including sterilization and decontamination of medical surfaces, medical devices for human skin, wound healing, treatment of dermatological diseases, cancer treatment, dentistry, and other related applications. ${ }^{3,4}$

A major problem in current therapeutical strategies for cancer is the lack of major efficiency followed by the relapse of cancer due to acquired drug resistance. As a result, there exists a dire need for novel cancer therapeutics and combination strategies. The success of future cancer treatment will rely on whether these alternative strategies can efficiently overcome current treatment limitations..$^{5}$ Therapeutic selectivity is associated with the level of normal tissue damage at a defined value of antitumor effect. Preliminary results from different research groups indicate that a selective response to plasma treatment may be achieved while exposing different cell types, with atmospheric plasma sources more active in targeting cancerous cells. ${ }^{6-18}$

The main types of discharges used so far for cancer cell exposure are helium plasma needles, plasma jets (operating in helium or argon), dielectric barrier discharges (DBDs) in air, and various electrode configurations and surface microdischarge (SMD). Helium-operated plasma needles have been used in hamster and mouse fibroblast treatment, with related studies reporting apoptosis and cell death. ${ }^{19,20}$ SMD treatment of human melanoma and glioblastoma cells led to apoptosis and senescence. ${ }^{21,22}$ DBD treatment on human cancer cells resulted in apoptosis, DNA damage, as well as the presence of intracellular reactive oxygen species (ROS) and selective cellular death. ${ }^{23-25}$ Plasma jet (both $\mathrm{He}$ and Ar) treatments induce cell cycle arrest, intracellular ROS, selective death, decreased metabolic activity, and alteration of gene expression. ${ }^{6,9,26,27}$

The treatment of HeLa cells using nonthermal plasmas has presented a major interest for various research groups. Previous study results have reported apoptosis, mitochondrial dysfunction, and cell membrane permeabilization. ${ }^{28,29}$ Hensel et al. studied the effects of an air transient spark discharge on HeLa cells compared with a helium plasma jet and reported the same cell cycle arrest, selectivity, and viability decreases. ${ }^{30}$ However, their results show minimal impact of the helium plasma jet compared to transient spark effects. These results point to the necessity of a slightly more aggressive discharge but with the use of reduced current values than those used with transient spark discharge.

Furthermore, DBD produced directly inside well plates used for growing cell cultures may minimize manipulation of cell cultures during exposures and biological assays. The well plates represent an additional dielectric for the discharge, also ensuring that the cells will not be affected by external factors until postexposure biological assessment.

This article focuses on the effects of air DBD discharge produced directly in well plates with HeLa (neoplastic cells) and Vero (normal cells) cell cultures. In addiiton, we emphasize selective response, viability, apoptosis, and TP53 gene expression. 


\section{MATERIALS AND METHODS}

\section{A. Experimental Setup and Plasma Diagnosis}

Air DBD plasma production inside standard cell-culture well plates must take into account a certain few particularities. First, the well plates must have minimum amount of manipulation to preserve the sterility of the system. This requires a discharge that does not affect the integrity of the electrodes and the well plate itself, eliminating any contamination risks. Second, the electrode system must ensure a volume discharge inside the well plates, with minimum power loss in the areas surrounding the wells. Taking into account these considerations, the air DBD used in this study creates a plasma volume inside the wells containing cell cultures, treating one column of the well plate at a time. The air DBD plasma system schematics is presented in Fig. 1, left.

An array of stainless-steel cylindrical electrodes connected through a copper plate was inserted in the well plate, with the number of cylinders in the array equal to the number of wells in the column (Fig. 1, right); specifically, eight electrodes (6-mm diameter) for the 96-well plate and four electrodes (14 mm diameter) for the 24-well plate. Electrode diameters were selected according to plate dimensions, ensuring no contact between them and the walls of the wells. A second planar electrode made of copper plate $(1.5-\mathrm{mm}$ thick) and covered with a thin $(0.1 \mathrm{~mm})$ dielectric layer was placed under the well plate, covering the entire bottom surface of the wells. Cell cultures were attached to the bottom of each well and covered with phosphate-buffered saline (PBS) solution throughout all of the treatments performed during the experiments $(50 \mu \mathrm{L}$ for the 96 -well plate; $100 \mu \mathrm{L}$ for

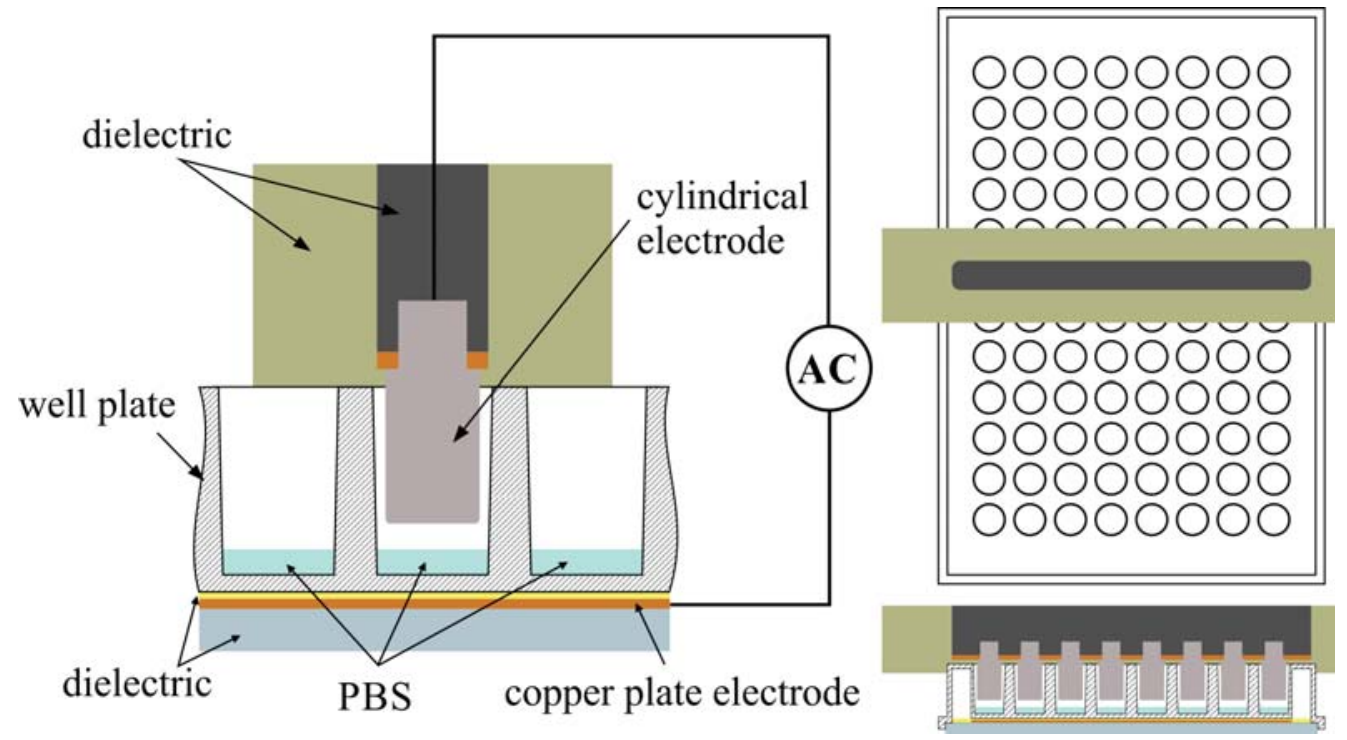

FIG. 1: Air DBD plasma experimental setup (left) and electrode position in a 96-well plate (right)

Volume 7, Issue 2, 2017 
the 24-well plate). A total gap (of PBS and air) of $3 \mathrm{~mm}$ between the electrode array and well plate bottom (Fig. 1, left) was kept constant during all experiments.

The discharge was sustained by alternating-current power supply $(50 \mathrm{~Hz})$ that provided a sinusoidal waveform, with a maximum of $15-\mathrm{kV}$ peak-to-peak voltage. A glow discharge with superimposed spark-like discharges formed inside the wells where the cylindrical electrodes were inserted. During the experiments, we noticed that the sparklike discharges had a tendency to ignite into the wells in the neighboring columns. In Fig. 2, we present typical discharge voltage and currents of DBD generated inside of the wells. The current trace, as returned by a Pearson 6585 monitor, represented the summation of the currents produced in all of the simultaneously exposed wells of one treated column.

The overall discharge consists of multiple discharge events grouped in packages corresponding to each rising and falling edge of the high-voltage (HV) sinusoidal wave. For each package (50-Hz frequency), individual current peaks, having tens of nanosecond duration and 2-250 mA amplitude, occurred at $\sim 10-\mathrm{kHz}$ frequency. These current measurements showed that the air DBD plasma produced inside the well plates was a

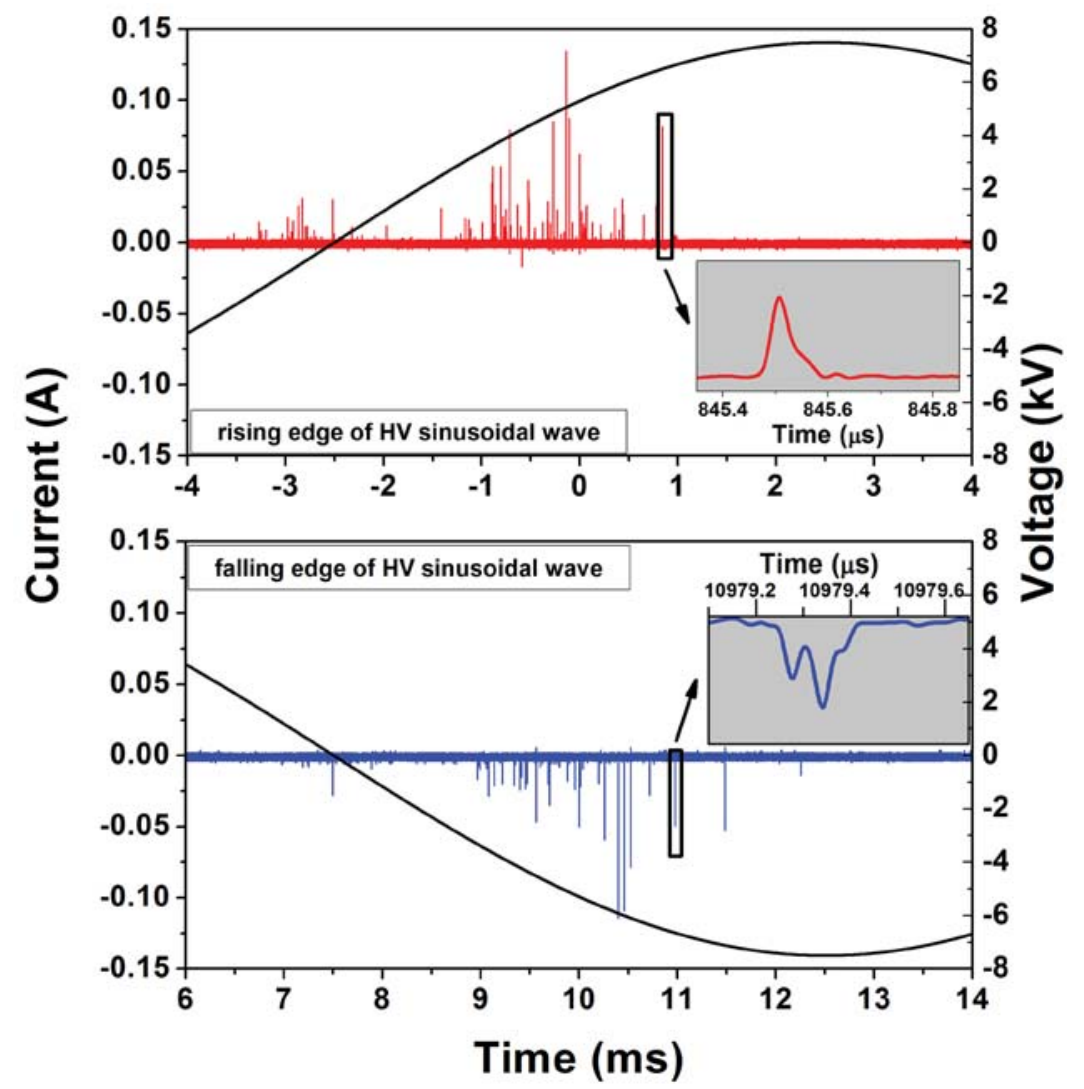

FIG. 2: Typical discharge voltage and current of DBD generated in a 24-well plate 
more aggressive discharge than a regular helium plasma jet (1-10-mA amplitude), having lower current values than a transient spark discharge (up to $10 \mathrm{~A}$ ). ${ }^{30}$

Optical emission spectroscopy was used to study emission spectra of air DBD plasma using a monochromator equipped with a charge-coupled device (CCD) detector (Triax 550 with Symphony CCD; Horiba Scientific; North Edison, NJ). The plasma emission spectrum (Fig. 3) mainly contains the signatures of the second positive system of molecular nitrogen (300-470-nm range): molecular nitrogen bands $\left(\mathrm{N}_{2}\right.$ from 306 to $380 \mathrm{~nm}$ and 399 to $405 \mathrm{~nm})$ and nitrogen molecular ions bands $\left(\mathrm{N}_{2}{ }^{+}\right.$from 391 to 470 $\mathrm{nm})$. In addition, emission lines corresponding to $\mathrm{H}(656.2 \mathrm{~nm})$ and $\mathrm{O}(777.4$ and 844.6 $\mathrm{nm})$ and the emission band corresponding to $\mathrm{OH}(306-310 \mathrm{~nm})$ are present but with significantly lower intensities. Finally, the spectrum shows artifacts as peaks specific to the second order of grating diffraction corresponding to molecular nitrogen (between 600 and $800 \mathrm{~nm}$ ).

An agent with significant importance in biological environments is the local heating provided by the discharge generated over the cell culture. Because proteins are present in cell structures and, most importantly, DNA material starts to degrade after a $40^{\circ} \mathrm{C}$ threshold value, we monitored temperature modification inside the treatment column wells to clarify whether plasma induced a thermal effect on the cell cultures. All wells of the 24- and 96-well plates were filled with the same quantity of PBS to cover the culture cells during treatment. Discharge was then switched on for various amounts of time. After switching the discharge off, the temperature of the liquid was measured using a type-K thermocouple. We found increases in liquid temperature to a maximum $22^{\circ} \mathrm{C}$ in the exposed column (Fig. 4), gradually decreasing in a lateral direction. Nevertheless,

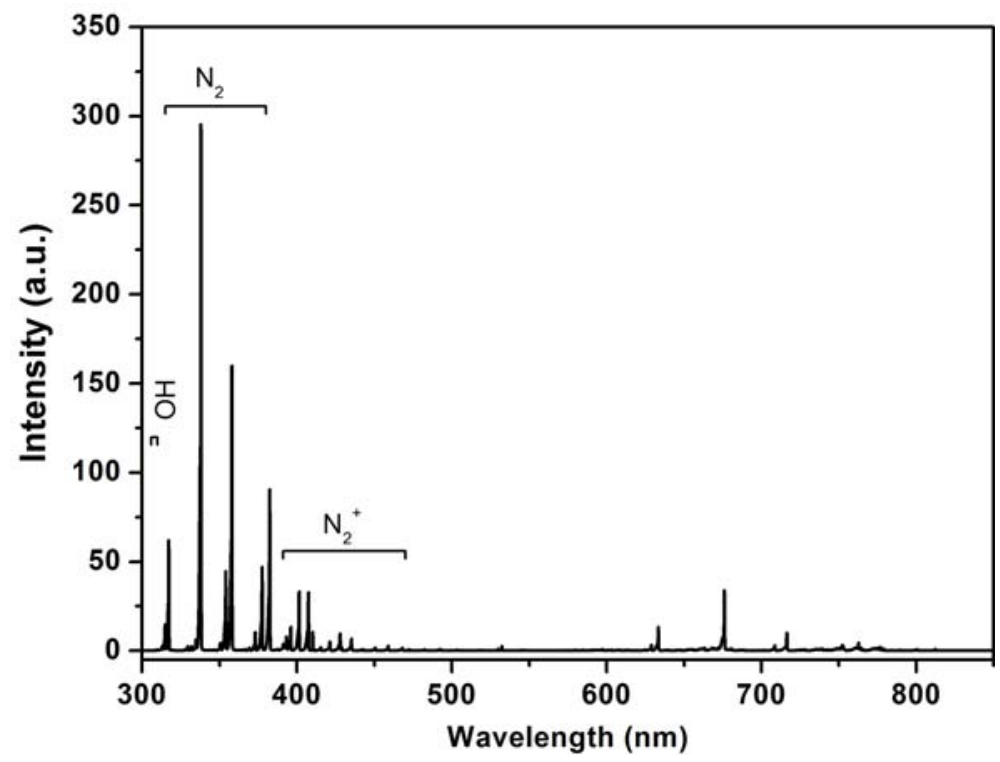

FIG. 3: Typical emission spectrum of air DBD plasma generated in a 24-well plate 

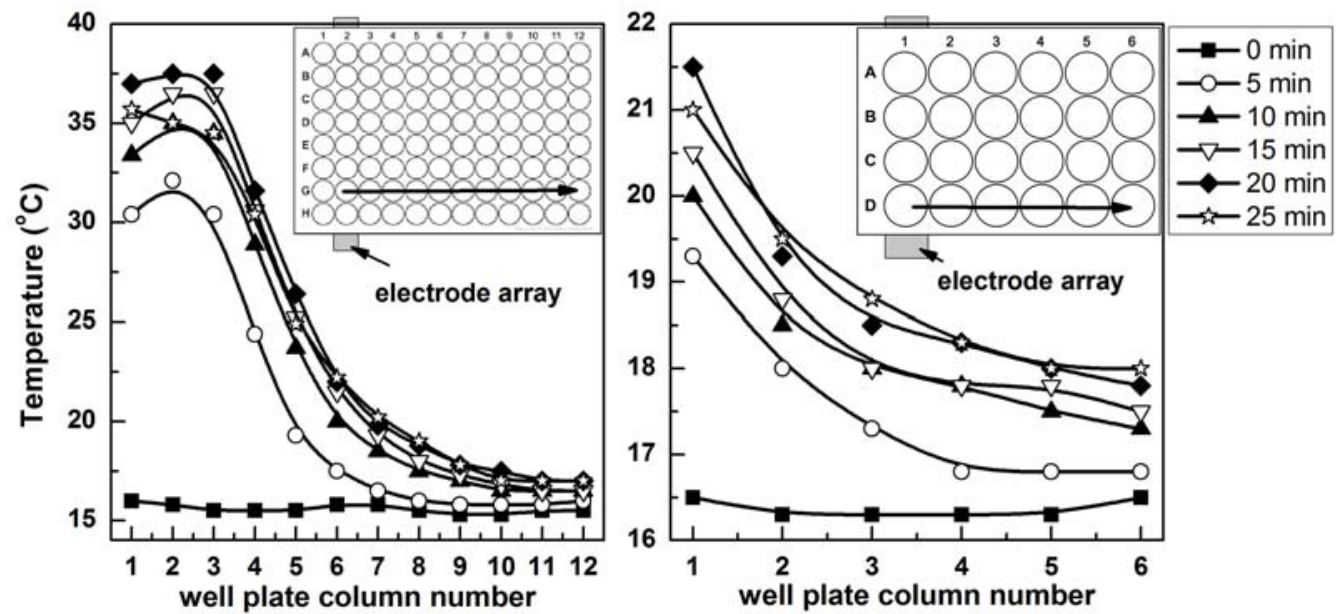

FIG. 4: Temperature evolution of the liquid in wells exposed to DBD generated in a 96-well plate (left) and a 24-well plate (right)

the measured temperature did not exceed $37^{\circ} \mathrm{C}$ in any electrode configuration. This ensured that discharge had no overall thermal effect on the cell cultures. The effects of air DBD plasma exposure on cell cultures were studied using peak-to-peak voltages of 10 , 12.5 , and $15 \mathrm{kV}$ and exposure times of $30 \mathrm{~s}$ to $25 \mathrm{~min}$.

\section{B. Cell Cultures and Biological Assays}

\section{Cell Cultures}

Biological material was represented by cell cultures of neoplastic cells (HeLa American Type Culture Collection [ATCC] CCL-2) and normal cells (Vero ATCC CCL-81) that were grown in Dulbeco's Modified Eagle's Medium (DMEM), supplemented with 10\% fetal bovine serum and antibiotics (streptomycin/penicillin) and maintained in a $5 \% \mathrm{CO}_{2}$ atmosphere with $95 \%$ humidity. For the viability assay, cells were seeded into 96-well plates at a density of $10^{4} /$ well. To test for apoptosis, we used a propidium iodide (PI) viability assay and gene expression, for which cells were seeded into 24 -well plates at a density of $4 \times 10^{4}$ cells/well for HeLa and $5 \times 10^{4}$ cells/well for Vero. Cells were allowed to grow overnight, and before exposure to plasma the medium was discarded and washed with PBS. Finally, for 96-well plates, $50 \mu \mathrm{L}$ of PBS was added, and for 24 -well plates, $100 \mu \mathrm{L}$ of PBS was added. After exposure, the cell layer was covered with fresh complete DMEM.

\section{Viability Assay}

We used the bromide assay 3-(4,5-dimethylthiazol-2-yl)-2,5-diphenyltetrazolium (MTT) method to evaluate cell viability $24 \mathrm{hr}$ after the treatment. Briefly, water-soluble 
MTT was converted to an insoluble formazan, which was then solubilized and the concentration determined by optical density at $540 \mathrm{~nm}$. At $24 \mathrm{hr}$ from plasma treatment, the medium was discarded, and cells were washed with PBS and covered with $100 \mu \mathrm{L}$ fresh complete medium. Then, $10 \mu \mathrm{L}$ of MTT $(5 \mathrm{mg} / \mathrm{mL})$ were added to the medium and incubated for $3 \mathrm{hr}$. To dissolve the formed formaza we used dimethylsulfoxide and took readings at $540 \mathrm{~nm}$.

\section{Apoptosis Assay}

We investigated apoptosis at $6 \mathrm{hr}$ after plasma treatment using an Annexin V-fluorescein isothiocyanate (FITC) (Abcam plc; Cambridge, UK)/PI assay. During apoptosis, phosphatidylserine is translocated from the cytoplasmic face of the plasma membrane to the cell surface. Annexin V has a strong affinity for phosphatidylserine residues on the surface of the cell, thus allowing discrimination between preapoptotic and apoptotic cells. PI is used to differentiate between dead and live cells. Briefly, the incubation medium was collected in individual tubes and cells were then rinsed with warm PBS and collected in the same tubes. Cell harvesting consisted of first detaching the cells by trypsinization and then successively washing with PBS and binding buffer (provided with the kit). Finally, cells were labeled with Annexin V-FITC and, after 30 min of incubation in the dark, with PI (provided in the eBioscience kit; Thermo Fisher Scientific; Waltham, MA). We performed the apoptosis analysis with a Cell Lab QuantaSC flow cytometer (Beckman Coulter; Brea, CA), equipped with a $488 \mathrm{~nm}$ laser as excitation source and suitable filters for fluorochromes selection. Output data were analyzed using flow cytometry data analysis software (Flowing Software; flowingsoftware.btk.fi).

\section{RNA Isolation and Quantitative Real-Time Polymerase Chain Reaction}

TP53 expression level was assessed after $4 \mathrm{hr}$ of air DBD plasma exposure. Treatment and control group cell cultures were sampled in 2-mL cryotubes and immediately prepared for RNA isolation. From all experimental variants, 90.000 to 100.000 cells per sample were resuspended in $175 \mu \mathrm{L}$ of RNA lysis buffer. Total RNA was isolated and purified using an SV Total RNA Isolation System kit (Promega; Madison, WI) according to manufacturer instructions. RNA concentration and integrity were determined by spectrophotometry, checking the A260/A280 ratio to assess the purity of the RNA. All samples exhibited an A260/A280 ratio $\geq 1.8$, with no intragroup or intergroup differences.

Reverse transcription and quantitative real-time polymerase chain reaction (qRTPCR) amplification was performed in single-step amplification reaction using the $\mathrm{GoTaq}^{\circledR}$ 1-Step RT-qPCR System (Promega; Madison, WI) on a fiveplex HRM Rotor Gene 6000 (Bosch Institute; Sydney, Australia) rotary RT-PCR. The reaction was carried out in 20 $\mu \mathrm{L}$ of total volume containing GoTaq Probe qPCR Master Mix 2X (Promega; Madison, WI), GoScript ${ }^{\mathrm{TM}}$ RT Mix for 1-Step RT-qPCR 50X (Promega; Madison, WI), forward and reverse primers, $100 \mathrm{ng}$ of transfer RNA template, and nuclease-free water up to vol-

Volume 7, Issue 2, 2017 
ume. To ensure that the amplification reaction was free of contaminants, a "no template control" was included for the TP53 amplified gene. To increase qRT-PCR accuracy, two independent runs were done with two replicates for each individual RNA sample.

We assessed the absolute expression level of TP53 by using predesigned specific primers for human cells including TP53 exon 5-300 nM forward and reverse primer mix (forward: 5'-CAGCACATGACGGAGGTTGT-3'; reverse: 5'-TCATCCAAATACTCCACACGC-3', 125 base-pair product size) (PrimerDesign; Southampton, UK). The thermal profile was a reverse transcription step for $15 \mathrm{~min}$ at $37^{\circ} \mathrm{C}$, RT inactivation/ hot-start activation for $10 \mathrm{~min}$ at $95^{\circ} \mathrm{C}, 40$ cycles of three-step qPCR $\left(10 \mathrm{~s}\right.$ at $95^{\circ} \mathrm{C}$ for denaturation, $30 \mathrm{~s}$ at $60^{\circ} \mathrm{C}$ for align and data collection [green channel SYBR Green 1 dye; Thermo Fisher Scientific; Waltham, MA], and $30 \mathrm{~s}$ at $72^{\circ} \mathrm{C}$ for elongation), and a dissociation step from $60^{\circ} \mathrm{C}$ to $95^{\circ} \mathrm{C}$.

Using PCR with the above primers, we obtained complementary DNA standards for the amplified gene. PCR product integrity was checked using agarose gel electrophoresis, purified using Agencourt AMPure XP (Beckman Coulter; Brea, CA) and quantified by a NanoDrop spectrophotometer (Thermo Fisher Scientific; Waltham, MA). Standard curve analyses were performed in duplicate for each serial dilution and quantified in the same run with samples. Each standard curve had six tenfold serial dilutions in duplicate, starting at $9.64 \times 10^{6}$ copies of TP53. The qRT-PCR run exhibited a reaction efficiency of $97 \%$ and an R2 value $>0.98$ for standard curves. The absolute expression level of each assayed gene was calculated as a concentration mean (copies/reaction) of 32 expression values for all of the cells from the exposed column. The level of TP53 was evaluated by absolute quantification using Rotor-Gene Q Pure Detection Software ver. 2.2.3 (QIAGEN; Hilden, Germany).

\section{RESULTS AND DISC USSON}

Initial exposure using time frames of $30 \mathrm{~s}$ to $5 \mathrm{~min}$ showed little to no statistically significant effects for both Vero and HeLa cell cultures. Exposure times $>5$ min showed a noticeable effect on cell cultures; however, after $20 \mathrm{~min}$, the quantity of PBS covering the cell culture decreased, disappearing almost completely after $25 \mathrm{~min}$. In addition, the effects induced in the cell cultures increased with higher-voltage values. To minimize exposure time and maximize effects, all investigations presented below were performed using a $15-\mathrm{kV}$ peak-to-peak voltage value and an exposure time of $10 \mathrm{~min}$.

To evaluate the cytotoxic impact of air DBD plasma on both HeLa and Vero cells, an MTT assay was performed. The exposure to DBD air plasma was performed in column 6 of a 96-well plate, filled with all wells filled with the same cell type. As can be observed in Fig. 5, at $24 \mathrm{hr}$ after exposure to DBD plasma, the viability of the HeLa cells significantly decreased in the exposed column (6) as well as in adjacent columns $(4,5$, 7 , and 8), whereas in the other columns, the cytotoxic impact was not as high. In the case of Vero cells, the pattern of cell response to the DBD plasma was similar to that of HeLa cells, but cytotoxicity was no more than $20 \%$ (column 5), whereas in the rest of the columns, a slight proliferative effect occurred (Fig. 5). 

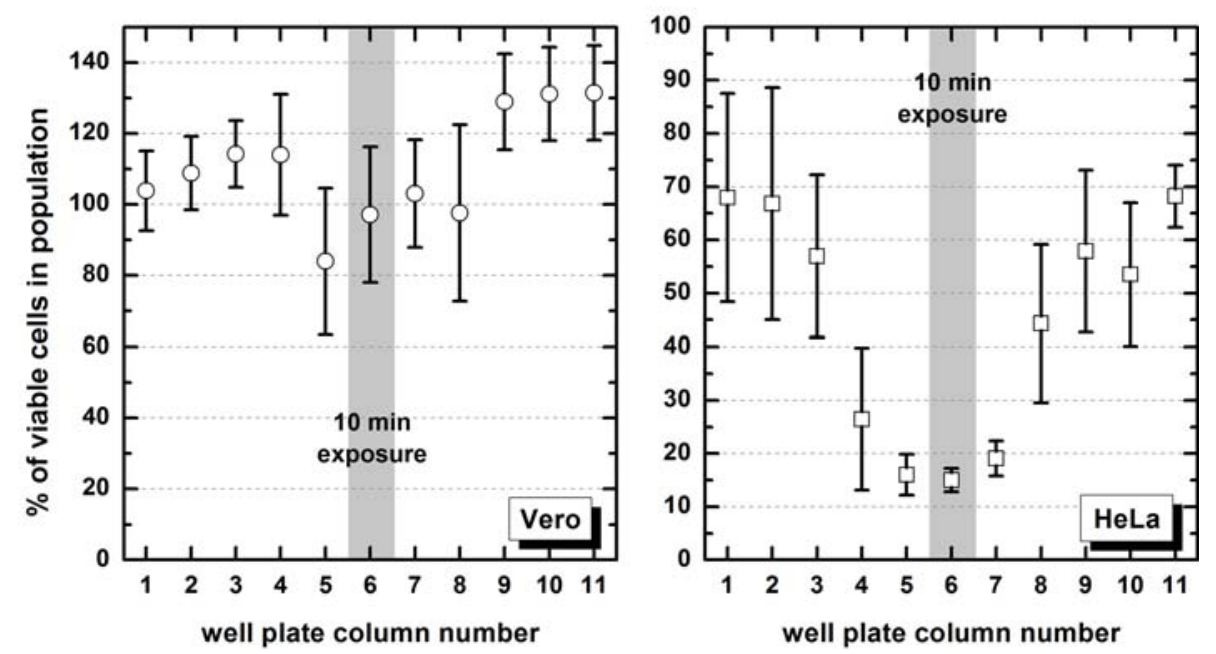

FIG. 5: Viability (MTT method) for Vero and HeLa cells at $24 \mathrm{hr}$ after 10-min exposure to air DBD plasma. All of the wells were filled with the same type of cells, and treatment was performed in column 6 of the well plate.

To obtain supplementary data about post-treatment cell viability to DBD plasma exposure (applied for $10 \mathrm{~min}$ ), HeLa and Vero cell viability was determined at 6 and $24 \mathrm{hr}$ (Fig. 6) by PI using the flow cytometric method. A significant decrease in cell viability of HeLa neoplastic cells occurred at $6 \mathrm{hr}$ (34\%); however, regarding the control group,
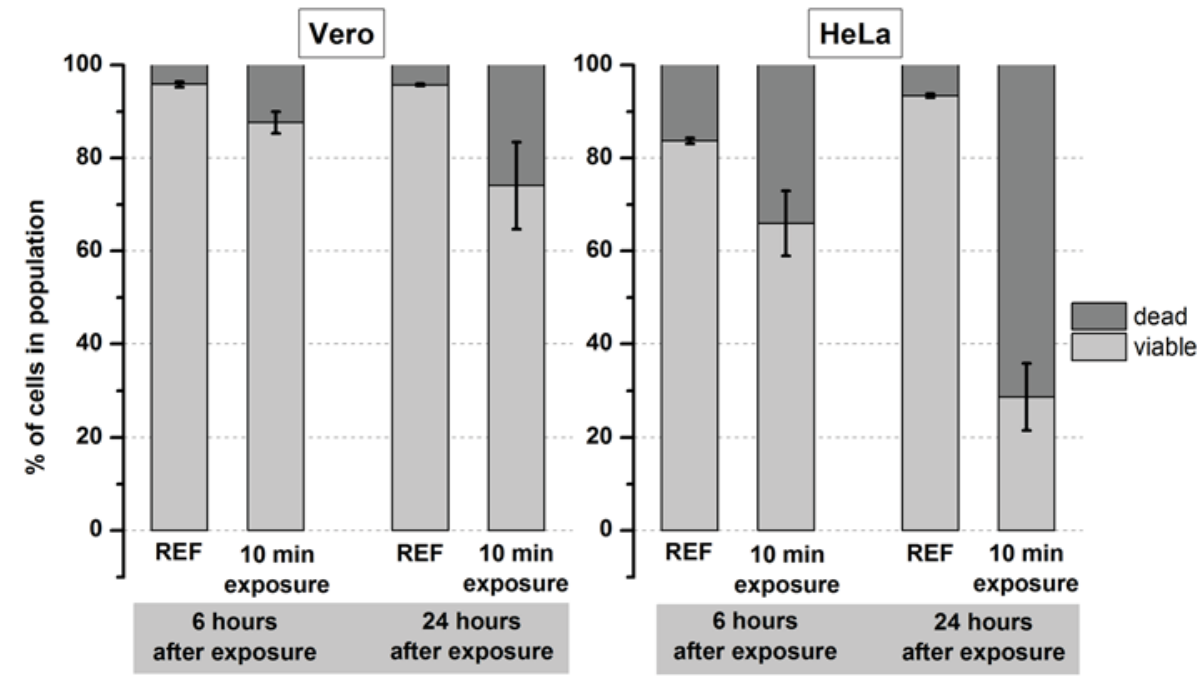

FIG. 6: Viability (flow cytometric method) for Vero and HeLa cells at 6 and $24 \mathrm{hr}$ after 10-min exposure to air DBD plasma. Only the wells of the treated columns were filled with same type of cells.

Volume 7, Issue 2, 2017 
which had a fraction of $16 \%$ dead or assimilated to the dead population, it can be said that the actual impact of the treatment was only $18 \%$. At $24 \mathrm{hr}$ after DBD plasma treatment, the fraction of dead cells was four times higher than that observed at $6 \mathrm{hr}$, with the dead cells representing $64 \%$ of the total number of cells. In the case of the normal Vero cells, viability was affected to a reduced degree by exposure to DBD plasma, reaching only $22 \%$ (subtracting the $4 \%$ from the control group) at $24 \mathrm{hr}$.

To further consider the mechanism underlying the effects of DBD plasma on cell viability and registered selectivity (observed to be three times more cytotoxic in neoplastic cells than in normal cells), apoptosis was investigated by Annexin V-FITC at $6 \mathrm{hr}$ after exposure. In comparison to the control group, levels of apoptotic and preapoptotic cells were elevated in the HeLa cell group exposed to plasma (Fig. 7). The amounts of dead cells were identical in the control and treated groups. The presence of a large fraction of apoptotic (20\%) and preapoptotic (7\%) cells alongside the dead cells $(15 \%)$ confirmed a registered decrease in viability at $6 \mathrm{hr}$, as demonstrated above. By subtracting the dead fraction registered in the control group, it could be seen that apoptosis in treated HeLa cells was not triggered immediately after DBD plasma exposure; instead, it had a certain delay, which was responsible for the elevated increase in cytotoxicity at $24 \mathrm{hr}$.

Regarding the normal cells, the frequency of cytotoxic effect in the different cell subpopulations as identified by flow cytometry (Annexin V-FITC assay) was similar to that of the reference group, with both at a small amount. Additionally, in the matter of both cell lines, the fraction of preapoptotic cells was similar (7\% HeLa, $8 \%$ Vero), suggesting a common course of DBD plasma but a different level of impairment depending on cell type (neoplastic or normal).

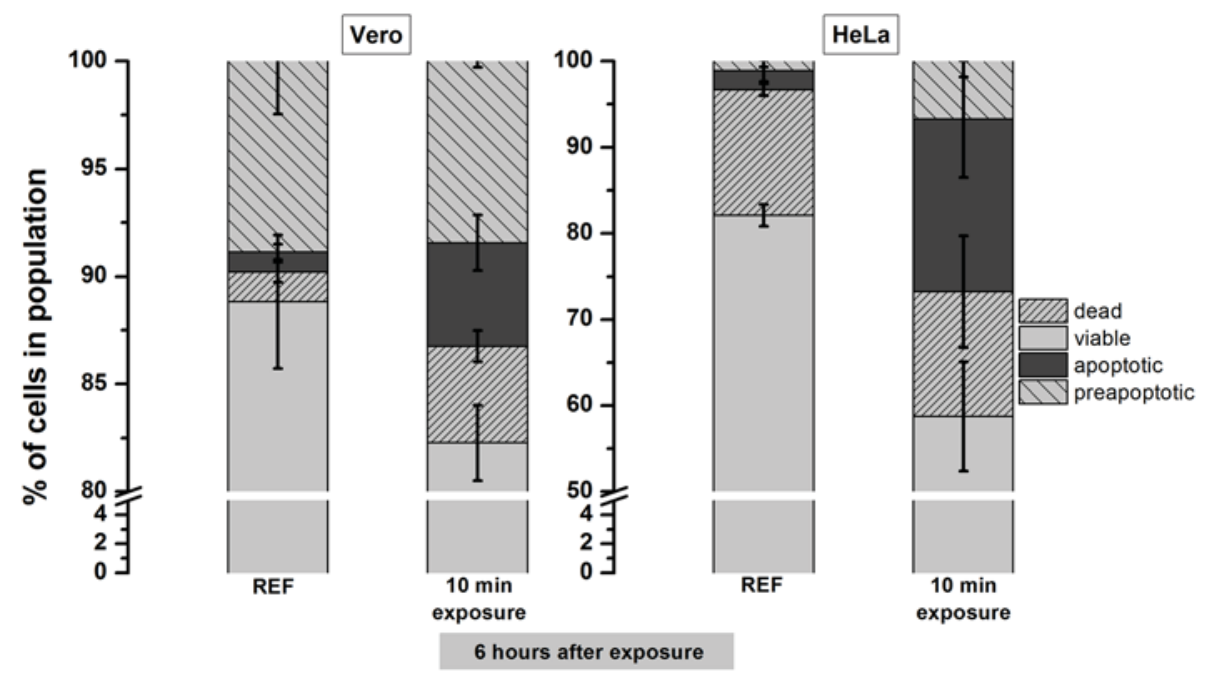

FIG. 7: Apoptosis for Vero and HeLa cells at $6 \mathrm{hr}$ after 10-min exposure to air DBD plasma. Only the wells of the treated columns were filled with same type of cells. 
The TP53 gene provides instructions for making a protein called tumor protein p53 (or p53). This protein acts as a tumor suppressor, in that it regulates cell division by keeping cells from growing and dividing too fast or in an uncontrolled way. Furthermore, $\mathrm{p} 53$ is a transcription factor present in a latent state in all cells and isactivated by various stressors such as hypoxia, free radicals, DNA damage, and ultraviolet (UV) light. ${ }^{31}$ This protein has a critical role in determining whether DNA will be repaired or the damaged cell will self-destruct (undergo apoptosis). If the DNA can be repaired, p53 activates other genes to fix the damage; otherwise, this protein prevents the cell from dividing and signals it to undergo apoptosis. By preventing cells with mutated or damaged DNA from dividing, p53 helps to block the development of tumors.

Cells committed to die via p53-dependent apoptosis typically follow the mitochondrial pathway, although p53 can also modulate cell death through death receptors. Furthermore, most evidence suggests that the key contribution of p53 to apoptosis is primarily dependent on transcriptional activity. p53 has the ability to activate transcription of various proapoptotic genes, including those encoding members of death proteins such as Bax, Peg3, Apaf1, p53AIP1, and Fas. ${ }^{32,33}$ Alternatively, p53 can also trigger apoptosis by repressing antiapoptotic genes, such as survivin, thus promoting caspase activation. ${ }^{34}$ New evidence suggests that p53 may also have immediate proapoptotic effects, independent of gene transcription, through the activation of mitochondrial apoptotic pathways. ${ }^{35,36}$ The importance of p53 in maintaining genome stability is exemplified by the finding that approximately half of all human tumors carry mutant p53.

Gene expression analysis uncovered the fact that the transcriptional level of the proapoptotic gene TP53, which was quantified $4 \mathrm{hr}$ after $10 \mathrm{~min}$ of exposure, was down-regulated as follows: $21.91 \%$ for Vero (ATCC CCL-81) cells and $41.04 \%$ for the wild-type HeLa (ATCC CCL-2) cells (Fig. 8). TP53 gene expression correlated with the annexin
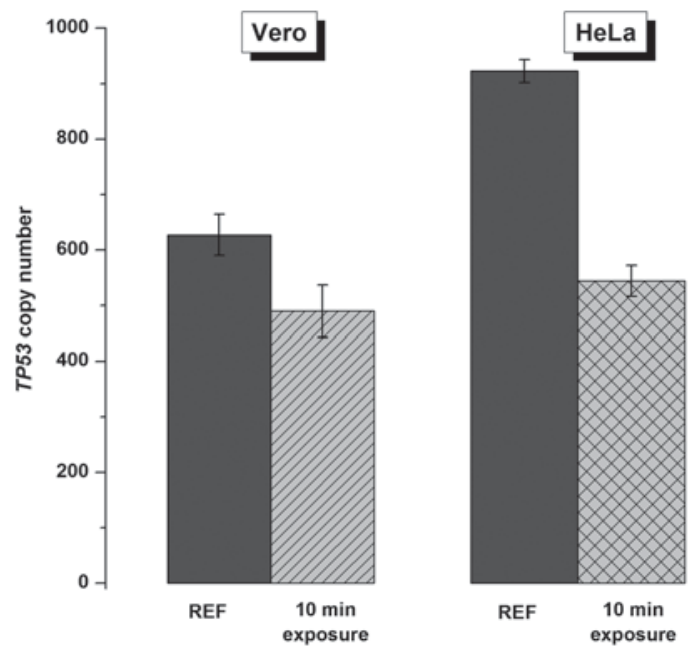

FIG. 8: Effects of air DBD plasma on transcriptional levels of the TP53 apoptotic-related gene

Volume 7, Issue 2, 2017 
5-FITC apoptosis assay, demonstrating that the apoptotic effect of air DBD plasma is not due to a cryptic transcription-dependent p53 function but, rather, to a different pathway.

Apoptosis was identified in our study as the main mechanism responsible for cell toxicity and selectivity, but the component of DBD plasma responsible for triggering apoptosis has not been clarified. The existence of various reactive oxygen and nitrogen species (suggested by Fig. 3 and data published on the subject ${ }^{37-40}$ ) could explain the induction of apoptosis and finally cell death. In this case, selectivity is based on the capacity of normal cells to adequately respond to oxidative stress, but in cancer cells, a supplementary oxidative stress (added to the already high levels within neoplastic cells) could be overwhelming the capacity to respond to oxidative stress, finally leading to cell death. In addition, continuous proliferation of neoplastic cells and their relative nonresponsiveness to external stimuli make them more susceptible to the action of different components of nonthermal plasma, thwarting their own protective systems. Low levels of p53 expression in both cell lines exposed to DBD plasma and the increased apoptosis in neoplastic cells could be viewed as contradictory, but in HeLa cells, ROS (especially hydrogen peroxide) triggers apoptosis by a mitochondrial pathway. ${ }^{41}$

The lateral effects recorded in the case of the 96-well plate viability assessment could be the consequence of few physicochemical agents acting in the area near the column exposed to plasma. Such agents include pulsed electric fields, known to act at a distance with considerable biological effects on cell membranes ${ }^{42,43}$; RONS transport through air, gel, and liquid media ${ }^{44,45}$; and stochastic generation of plasma filaments around the pin-electrode array, concentrating plasma agents for short duration and inducing damage to biological soft matter. ${ }^{46-48}$ The stochastic behavior of these longdistance factors is very well emphasized by the standard deviation level of the cell population in Fig. 5, around the plasma-exposed column. In the HeLa treated group, the cells from adjacent columns are affected, but the same occurrence has minor impact on normal cells, confirming the selectivity of DBD plasma. Moreover, the cytotoxic effect was not limited to the area of application. This behavior could be used to an advantage in anticancer therapy by applying plasma to resection margins after surgery to reduce residual neoplastic cells.

\section{IV.CONCLSIONS}

In this study, we successfully demonstrated the possibility of generating nonthermal air DBD plasma inside the well of cell-culture plates. Using an appropriate electrode configuration, an HV power supply, and the polystyrene well plate acting as a dielectric, DBD plasma with a controlled air gap can be generated inside the desired number of wells. The overall thermal effect on cells is negligible in this discharge configuration, with other factors responsible for plasma biological effects, including charge transport, pulsed electric field, pulsed UV light, RONS generation, and transport.

After we studied plasma cytotoxicity on normal cells (Vero) and neoplastic cells (HeLa) using different methods, we found a reduction in viable cells in both cell lines. However, the magnitude of the effect was greater for neoplastic cells. Selectivity of 
nonthermal plasma was based on the capacity to induce modifications in the normal cytophysiology of neoplastic cells, triggering apoptosis. The down-regulation of p53 in HeLa cells could be due to activation of an alternative apoptotic pathway (mitochondrial) in response to oxidative stress.

Interestingly, the influence of air DBD plasma on cell viability was not only limited to treatment area; a lateral effect was seen, with spreading occurring in surrounding cell cultures. If this lateral effect is observed for other cell cultures using other discharge configurations, it could represent a major advantage of nonthermal plasma for cancer therapy. Together with observed selectivity, the relatively long-distance action of plasma active agents can be used to damage residual neoplastic cells and limit their survival after surgery.

\section{ACKNOWEDGMENIS}

This work was supported by Alexandru Ioan Cuza University of Iasi under Grant No. GI-2015-06, by way of the internal grant competition for young researchers. We thank the POSCCE-O 2.2.1, SMIS-CSNR 13984-901, No. 257/28.09.2010 Project CERNESIM for the infrastructure used in this work.

\section{REFERENCES}

1. Winter J, Brandenburg R, Weltmann K-D. Atmospheric pressure plasma jets: An overview of devices and new directions. Plasma Sources Sci Technol. 2015 Oct 8;24(6):064001.

2. Kogelschatz U. Atmospheric-pressure plasma technology. Plasma Phys Controlled Fusion. 2004 Nov 18;46(12B):B63.

3. von Woedtke T, Metelmann H-R, Weltmann K-D. Clinical plasma medicine: State and perspectives of in vivo application of cold atmospheric plasma. Contrib Plasma Phys. 2014 Feb 1;54(2):104-17.

4. Kong MG, Kroesen G, Morfill G, Nosenko T, Shimizu T, van Dijk J, Zimmermann JL. Plasma medicine: An introductory review. New J Phys. 2009 Nov 26;11(11):115012.

5. Miller MJ, Foy KC, Kaumaya PTP. Cancer immunotherapy: Present status, future perspective, and a new paradigm of peptide immunotherapeutics. Discov Med. 2013 Mar;15(82):166-76.

6. Georgescu N, Lupu AR. Tumoral and normal cells treatment with high-voltage pulsed cold atmospheric plasma jets. IEEE Trans Plasma Sci. 2010;38(8):1949-55.

7. Vandamme M, Robert E, Lerondel S, Sarron V, Ries D, Dozias S, Sobilo J, Gosset D, Kieda C, Legrain B, Pouvesle J-M, Pape AL. ROS implication in a new antitumor strategy based on non-thermal plasma. Int J Cancer. 2012 May 1;130(9):2185-94.

8. Partecke LI, Evert K, Haugk J, Doering F, Normann L, Diedrich S, Weiss F-U, Evert M, Huebner NO, Guenther C, Heidecke CD, Kramer A, Bussiahn R, Weltmann K-D, Pati O, Bender C, von Bernstorff W. Tissue tolerable plasma (TTP) induces apoptosis in pancreatic cancer cells in vitro and in vivo. BMC Cancer. 2012 Oct 15;12:473.

9. Volotskova O, Hawley TS, Stepp MA, Keidar M. Targeting the cancer cell cycle by cold atmospheric plasma. Sci Rep. 2012 Sep 6;2:636.

10. Keidar M, Shashurin A, Volotskova O, Stepp MA, Srinivasan P, Sandler A, Trink B. Cold atmospheric plasma in cancer therapy. Phys Plasmas. 2013;20(5):057101.

11. Ninomiya K, Ishijima T, Imamura M, Yamahara T, Enomoto H, Takahashi K, Tanaka Y, Uesugi Y, Shimizu N. Evaluation of extra- and intracellular $\mathrm{OH}$ radical generation, cancer cell injury, and apoptosis induced by a non-thermal atmospheric-pressure plasma jet. J Phys D Appl Phys. 2013;46(42):425401.

Volume 7, Issue 2, 2017 
12. Schlegel J, Köritzer J, Boxhammer V. Plasma in cancer treatment. Clin Plasma Med. 2013;1(2):2-7.

13. Chang JW, Kang SU, Shin YS, Kim KI, Seo SJ, Yang SS, Lee J-S, Moon E, Lee K, Kim C-H. Nonthermal atmospheric pressure plasma inhibits thyroid papillary cancer cell invasion via cytoskeletal modulation, altered MMP-2/-9/uPA activity. PLoS ONE. 2014 Mar 25;9(3):e92198.

14. Ratovitski EA, Cheng X, Yan D, Sherman JH, Canady J, Trink B, Keidar M. Anti-cancer therapies of 21st century: Novel approach to treat human cancers using cold atmospheric plasma. Plasma Proc Polym. 2014;11(12):1128-37.

15. Keidar M, Walk R, Shashurin A, Srinivasan P, Sandler A, Dasgupta S, Ravi R, Guerrero-Preston R, Trink B. Cold plasma selectivity and the possibility of a paradigm shift in cancer therapy. Br J Cancer. 2011 Oct 25;105(9):1295-301.

16. Guerrero-Preston R, Ogawa T, Uemura M, Shumulinsky G, Valle BL, Pirini F, Ravi R, Sidransky D, Keidar M, Trink B. Cold atmospheric plasma treatment selectively targets head and neck squamous cell carcinoma cells. Int J Mol Med. 2014 Oct;34(4):941-6.

17. Ma Y, Ha CS, Hwang SW, Lee HJ, Kim GC, Lee K-W, Song K. Non-thermal atmospheric pressure plasma preferentially induces apoptosis in p53-mutated cancer cells by activating ROS stress-response pathways. PLoS ONE. 2014 Apr 23;9(4):e91947.

18. Naciri M, Dowling D, Al-Rubeai M. Differential sensitivity of mammalian cell lines to non-thermal atmospheric plasma. Plasma Proc Polym. 2014;11(4):391-400.

19. Kieft IE, Broers JLV, Caubet-Hilloutou V, Slaaf DW, Ramaekers FCS, Stoffels E. Electric discharge plasmas influence attachment of cultured CHO K1 cells. Bioelectromagnetics. 2004 Jul;25(5): $362-8$.

20. Stoffels E, Kieft IE, Sladek REJ, van den Bedem LJM, van der Laan EP, Steinbuch M. Plasma needle for in vivo medical treatment: recent developments and perspectives. Plasma Sources Sci Technol. 2006 Oct 6;15(4):S169.

21. Arndt S, Wacker E, Li Y-F, Shimizu T, Thomas HM, Morfill GE, Karrer S, Zimmermann JL, Bosserhoff A-K. Cold atmospheric plasma, a new strategy to induce senescence in melanoma cells. Exp Dermatol. 2013 Apr;22(4):284-9.

22. Köritzer J, Boxhammer V, Schäfer A, Shimizu T. Restoration of sensitivity in chemo-resistant glioma cells by cold atmospheric plasma. PLoS ONE. 2013;8(5):e64498.

23. Kalghatgi S, Kelly CM, Cerchar E, Torabi B, Alekseev O, Fridman A, Friedman G, Azizkhan-Clifford J. Effects of non-thermal plasma on mammalian cells. PLoS ONE. 2011 Jan 21;6(1):e16270.

24. Panngom K, Baik KY, Nam MK, Han JH, Rhim H, Choi EH. Preferential killing of human lung cancer cell lines with mitochondrial dysfunction by nonthermal dielectric barrier discharge plasma. Cell Death Dis. 2013 May 23;4:e642.

25. Kaushik NK, Attri P, Kaushik N, Choi EH. A preliminary study of the effect of DBD plasma and osmolytes on T98G brain cancer and HEK non-malignant cells. Molecules. 2013 Apr 25;18(5):4917-28.

26. Yan X, Xiong Z, Zou F, Zhao S, Lu X, Yang G, He G, Ostrikov K. Plasma-induced death of HepG2 cancer cells: Intracellular effects of reactive species. Plasma Proc Polym. 2012 Jan 1;9(1):59-66.

27. Schmidt A, Wende K, Bekeschus S, Bundscherer L, Barton A, Ottmüller K, Weltmann K-D, Masur K. Non-thermal plasma treatment is associated with changes in transcriptome of human epithelial skin cells. Free Radic Res. 2013 Aug;47(8):577-92.

28. Leduc M, Guay D, Leask RL, Coulombe S. Cell permeabilization using a non-thermal plasma. New J Phys. 2009 Nov 26;11(11):115021.

29. Ahn HJ, Kim KI, Kim G, Moon E, Yang SS, Lee J-S. Atmospheric-pressure plasma jet induces apoptosis involving mitochondria via generation of free radicals. PLoS ONE. 2011 Nov 29;6(11):e28154.

30. Hensel K, Kučerová K, Tarabová B, Janda M, Machala Z, Sano K, Mihai CT, Ciorpac M, Gorgan LD, Jijie R, Pohoata V, Topala I. Effects of air transient spark discharge and helium plasma jet on water, bacteria, cells, and biomolecules. Biointerphases. 2015 Jun 6;10(2):029515.

31. Vousden KH. Activation of the p53 tumor suppressor protein. Biochim Biophys Acta. 2002 Mar 14;1602(1):47-59. 
32. Bargonetti J, Manfredi JJ. Multiple roles of the tumor suppressor p53. Curr Opin Oncol. 2002 Jan;14(1):86-91.

33. Vousden KH, Lu X. Live or let die: The cell's response to p53. Nat Rev Cancer. 2002 Aug;2(8):594-604.

34. Hoffman WH, Biade S, Zilfou JT, Chen J, Murphy M. Transcriptional repression of the anti-apoptotic surviving gene by wild type p53. J Biol Chem. 2002 Feb 1;277(5):3247-57.

35. Regula KM, Kirshenbaum LA. p53 Activates the mitochondrial death pathway and apoptosis of ventricular myocytes independent of de novo gene transcription. J Mol Cell Cardiol. 2001 Aug;33(8): $1435-45$.

36. Mihara M, Erster S, Zaika A, Petrenko O, Chittenden T, Pancoska P, Moll UM. p53 has a direct apoptogenic role at the mitochondria. Mol Cell. 2003 Mar;11(3):577-90.

37. Thiyagarajan M, Anderson H, Gonzales XF. Induction of apoptosis in human myeloid leukemia cells by remote exposure of resistive barrier cold plasma. Biotechnol Bioeng. 2014 Mar;111(3):565-74.

38. Cheng X, Sherman J, Murphy W, Ratovitski E, Canady J, Keidar M. The effect of tuning cold plasma composition on glioblastoma cell viability. PLoS ONE. 2014 May 30;9(5):e98652.

39. Simon HU, Haj-Yehia A, Levi-Schaffer F. Role of reactive oxygen species (ROS) in apoptosis induction. Apoptosis. 2000 Nov;5(5):415-8.

40. Circu ML, Aw TY. Reactive oxygen species, cellular redox systems, and apoptosis. Free Radic Biol Med. 2010 Mar 15;48(6):749-62.

41. Singh M, Sharma H, Singh N. Hydrogen peroxide induces apoptosis in HeLa cells through mitochondrial pathway. Mitochondrion. 2007 Dec;7(6):367-73.

42. Panagopoulos DJ, Karabarbounis A, Margaritis LH. Mechanism for action of electromagnetic fields on cells. Biochem Biophys Res Commun. 2002 Oct 18;298(1):95-102.

43. Teissié J, Escoffre J, Rols M, Golzio M. Time dependence of electric field effects on cell membranes. A review for a critical selection of pulse duration for therapeutical applications. Radiol Oncol. 2008;42(4):196-206.

44. Kawasaki T, Sato A, Kusumegi S, Kudo A, Sakanoshita T, Tsurumaru T, Uchida G, Koga K, Shiratani M. Two-dimensional concentration distribution of reactive oxygen species transported through a tissue phantom by atmospheric-pressure plasma-jet irradiation. Appl Phys Express. 2016 Jun 20;9(7):076202.

45. Kawasaki T, Kusumegi S, Kudo A, Sakanoshita T, Tsurumaru T, Sato A, Uchida G, Koga K, Shiratani M. Effects of irradiation distance on supply of reactive oxygen species to the bottom of a Petri dish filled with liquid by an atmospheric $\mathrm{O}_{2} /$ He plasma jet. J Appl Phys. 2016 May 3;119(17):173301.

46. Chernets N, Zhang J, Steinbeck MJ, Kurpad DS, Koyama E, Friedman G, Freeman TA. Nonthermal atmospheric pressure plasma enhances mouse limb bud survival, growth, and elongation. Tissue Eng Part A. 2015 Jan;21(1-2):300-9.

47. Hertwig C, Steins V, Reineke K, Rademacher A, Klocke M, Rauh C, Schlüter O. Impact of surface structure and feed gas composition on Bacillus subtilis endospore inactivation during direct plasma treatment. Front Microbiol. 2015 Aug 6;6:774.

48. Kim KC, Piao MJ, Madduma Hewage SRK, Han X, Kang KA, Jo JO, Mok YS, Shin JH, Park Y, Yoo SJ, Hyun JW. Non-thermal dielectric-barrier discharge plasma damages human keratinocytes by inducing oxidative stress. Int J Mol Med. 2016 Jan;37(1):29-38.

Volume 7, Issue 2, 2017 